$$
\begin{aligned}
& \text { SAND98-0781C } \\
& \text { SAND-98-0781C } \\
& \text { CONF-980353-- }
\end{aligned}
$$

\title{
RESULTS OF PERFORMANCE TESTING THE RUSSIAN RPV TEMPERATURE MEASUREMENT PROBE USED FOR ANNEALING
}

\author{
RECEIVEO \\ BY \\ APR 071938 \\ Q.णT। \\ James T. Nakos \\ Sandia National Laboratories \\ Albuquerque, NM \\ and \\ Sergei Selsky \\ CNIITMASH \\ Moscow, Russia
}
Paper Presented at the EPRI Thermal Annealing Conference Santa Fe, NM

March 31-April 1, 1998

DISTRBSUTION OF THIS DOCUMENT IS UNUMITED 


\section{DISCLAIMER}

This report was prepared as an account of work sponsored by an agency of the United States Government. Neither the United States Government nor any agency thereof, nor any of their employees, makes any warranty, express or implied, or assumes any legal liability or responsibility for the accuracy, completeness, or usefulness of any information, apparatus, product, or process disclosed, or represents that its use would not infringe privately owned rights. Reference herein to any specific commercial product, process, or service by trade name, trademark, manufacturer, or otherwise does not necessarily constitute or imply its endorsement, recommendation, or favoring by the United States Government or any agency thereof. The views and opinions of authors expressed herein do not necessarily state or reflect those of the United States Government or any agency thereof. 


\section{ABSTRACT}

This paper provides information on three (3) topics related to temperature measurements in an annealing procedure: 1) results of a series of experiments performed by CNIITMASH of the Russian consortium MOHT on their reactor pressure vessel (RPV) temperature measurement probe, 2) a discussion regarding uncertainties and errors in RPV temperature measurements, and 3) predictions from a thermal model of a spherical RPV temperature measurement probe. MOHT teamed with MPR Associates and was to perform the Annealing Demonstration Project (ADP) on behalf of the US Department of Energy, ESEERCo, EPRI, CRIEPI, Framatome, and Consumers Power Co. at the Midland plant. Experimental results show that the CNIITMASH probe errors are a maximum of about $27^{\circ} \mathrm{C}\left(49^{\circ} \mathrm{F}\right)$ during a $15^{\circ} \mathrm{C} / \mathrm{hr}\left(27^{\circ} \mathrm{F} / \mathrm{hr}\right)$ heat-up but only about $3^{\circ} \mathrm{C}$ $\left(5.4^{\circ} \mathrm{F}\right)(0.6 \%)$ during the hold portion at $470^{\circ} \mathrm{C}\left(878^{\circ} \mathrm{F}\right)$. These errors are much smaller than those obtained from a similar series of experiments performed by Sandia National Laboratories (Sandia). The discussion about uncertainties and errors shows that results presented as a temperature difference provides a measure of the probe error. Qualitative agreement is shown between the model predictions, the experimental results of the CNITMASH probe and the experimental results of a series of similar experiments performed by Sandia.

\section{INTRODUCTION}

One can argue that the most important group of temperature measurements in an annealing procedure is the temperature of the reactor pressure vessel (RPV). These are important because the RPV temperature has to be high enough to assure an effective anneal, but low enough to preclude any creep effects and excessive stress on the RPV, nozzles and reactor coolant system (RCS) piping. It is generally desired that the RPV temperature stay in the $800-900^{\circ} \mathrm{F}$ range during the constant temperature portion of the annealing treatment. During the heat-up and cool-down portions, spatial temperature gradients must be kept below allowable limits. It is possible to measure the RPV temperature on the inside and outside, but as is sometimes the case (e.g., at Marble Hill) gaining access to the RPV walls from the outside is difficult due to space limitations. There is ample space to attach temperature measuring sensors on the inside of the RPV, but due to radiation concerns in an operating plant and the desire not to disturb the inside of the RPV, probes that touch, but are not attached to the RPV surface are most desirable.

Sandia has performed many similar measurements in the past and was aware of some of the errors that could occur in measuring the temperature of a surface being heated radiatively without being able to firmly attach the sensor to the surface. Significant errors can result if the probe is not designed properly.

Sandia is a multiprogram laboratory operated by Sandia Corporation, a Lockheed Martin Company, for the United States Department of Energy under Contract DE-AC04-94AL85000. 
Based on the literature available on the Russian design [1], Sandia was concerned that the probes described would not produce sufficiently accurate measurements. As a result, Sandia fabricated a number of probes based on the description provided in [1] and ran a series of experiments to determine their accuracy. Results published in [2] showed that large errors (e.g., over $100^{\circ} \mathrm{F}$ during the heat-up portion and up to about $5 \%\left( \pm 40^{\circ} \mathrm{F}\right)$ during the hold portion) occurred in some probe designs. That information was transmitted to both ADP teams and both teams tested their probe designs to quantify the errors of their designs.

This paper discusses uncertainties and errors in RPV temperature measurements and how they relate to the experimental data presented. Then, the results of a series of small scale experiments are presented. These were performed by CNIITMASH, the furnace fabricator, in Moscow, Russia to quantify the errors of the Russian RPV temperature measurement probe design. As the results will show, the Russian design provides both stable and accurate measurements, with a small offset during the heat-up and cool-down and small errors (e.g., $1 \%$ ) during the hold portion at $470^{\circ} \mathrm{C}\left(878^{\circ} \mathrm{F}\right)$. The reason that the Sandia experiments and the CNITMASH experiments did not agree was that the information provided in [1] was not descriptive enough for Sandia to accurately reproduce the Russian probe design. Lastly, this paper discusses a thermal model of a spherical probe, compares model predictions to experimental data, and provides insights as to how the probe design may be improved based on the model.

\section{EXPERIMENTAL SETUP}

The CNIITMASH and Sandia experimental setups were similar. They both consisted of a bank of automatically controlled electric resistance heaters, a rectangular piece of steel to simulate the RPV wall, several RPV temperature measurement probes, "reference" thermocouples firmly attached to the RPV wall, and ancillary equipment

The Russian setup consisted of a mild steel plate 81 in wide, 28 in tall and 3.9 in thick to simulate the RPV wall. Two electric infrared heaters were placed 9.8 in from the wall section. Maximum temperature of the heaters was about $1000^{\circ} \mathrm{C}\left(1832^{\circ} \mathrm{F}\right)$. Two retractable RPV temperature measurement probes (called "probes" for short) (TC3 and TC6) were pressed against the wall section. Near where each probe touched the wall two thermocouples were firmly attached to the wall (TC1 and TC2 for probe TC3; TC4 and TC5 for probe TC6). Thermocouples TC1, TC2, TC4, TC5 were considered to be the "exact" temperature of the RPV wall, although they too have some finite error, and are called the "reference" temperatures. The reference temperature thermocouples were also Type K (chromel-alumel) but were intrinsically attached (i.e., each wire was attached) to the wall. The wire diameter was $0.5 \mathrm{~mm}$ with $1 \mathrm{~mm}$ of the measuring junction attached to the wall. The probes were pressed onto the RPV wall. Because the design of the probe is proprietary, it will not be described here. Suffice it to say the overall probe size is that of a ping-pong ball (but not a spherical shape). Figure 1 shows a top view of the Russian setup. 
The Sandia experimental setup is similar to that of the Russian setup. Details of the Sandia setup are provided in [2]; a brief description follows. The wall section was 48 in $\mathrm{x}$ 48 in x 6.75 in thick and composed of A533 Grade B steel with a 0.13-0.19 in thick stainless steel cladding. A $3 \times 3$ heater bank composed of 9 individual heaters about $2 \mathrm{ft}$ $\mathrm{x} 2 \mathrm{ft}$ each were placed nominally 10 in away from the wall section. There were 3 control channels, each channel controlled a row of three heater panels. Similar to the Russian experiments the heaters were feedback controlled from control thermocouples attached to the wall section. The Sandia experiments also had reference thermocouples attached to the wall section close to where the probes touched the wall. The Sandia reference thermocouples were $1.6 \mathrm{~mm}$ (1/16 in) diameter stainless steel sheathed, Type $\mathrm{K}$. These sheathed thermocouples were spot-welded to the wall via nichrome strips.

\section{ERROR/UNCERTAINTY ANALYSIS}

The purpose of this section is to provide a theoretical basis for the experimental results to be presented later. An estimate of the probe error will be presented in the next section; the results will be presented as a temperature difference between the probe and reference temperature.

\section{Overview}

Based on [3] or [4], the overall error of any measurement may be separated into two parts, a "bias" error and a "random" or "systematic" error. The bias error is an offset, for example the fact that the RPV temperature measurement probes read higher than the reference thermocouples during the heat-up. The random or systematic error (also called "precision") is that part one can observe from repeated measurements, and can only be estimated from statistical methods. As the name implies, these are random in nature, and therefore may be better described as an uncertainty. To decide if a given error source contributes to bias or random error, the following recommendation is often adopted: "The uncertainty of a measurement should be put into one of two categories depending on how the uncertainty is derived. A random uncertainty is derived by statistical analysis of repeated independent measurements while a systematic [i.e., bias] uncertainty is estimated by non-statistical methods." [3] Bias and random errors may be separated into three categories [3]:

1) Calibration errors

2) Data acquisition errors

3) Data reduction errors

Each of these categories will be briefly described next. 


\section{1) Calibration Errors}

These refer to the errors in the calibration process, which includes items such as errors in the calibration measuring equipment, and errors related to the process of calibrating the measuring system from a standards laboratory, through an inter-laboratory standard, a transfer standard, a working standard, to the actual measuring instrument used. The main purpose of the calibration process is to reduce or eliminate known bias errors by "exchanging the large bias error of an uncalibrated or poorly calibrated instrument for the smaller combination of the bias error of the standard instrument and the precision (random) error of the comparison" [3]. Examples of calibration errors are the error limits for Type K thermocouples (see [5]) and thermocouple extension wire.

\section{2) Data Acquisition}

These refers to those categories that are part of the data acquisition process. Examples include the errors in the data acquisition hardware used to gather the data (e.g., error in the voltmeter reading), environmental effects, spacial averaging, location uncertainty, and what is often the largest source of error, that due to the manner in which the probe is mounted to the surface being measured. Contributors to mounting method errors include imperfect thermal contact between the probe and wall, conduction heat transfer along the thermocouple wires of the probe, differences in the dynamic response of the probe and wall due to free convection, and differing dynamic responses due to the radiative heat transfer from the heaters.

\section{3) Data Reduction}

These refers to those errors associated with conversion of the voltage readings to a temperature (curve fit), truncation and roundoff errors, and engineering unit conversion. Many voltage to temperature conversion equations exist for Type $\mathrm{K}$ thermocouples, usually in the form of several polynomials, each spanning a certain temperature range. Some polynomials that span large temperature ranges can have uncertainties of about $1^{\circ} \mathrm{C}$ $\left(1.8^{\circ} \mathrm{F}\right)$; others have much smaller uncertainties. This type of data reduction error has both a bias and random part. The bias part stems from the error caused by the conversion from voltage to temperature, varies with temperature, and may change sign (i.e., the bias at $100^{\circ} \mathrm{F}$ is likely different than the bias at $800^{\circ} \mathrm{F}$.) The random part stems from uncertainty in the thermoelectric EMF generated by a thermocouple type at each temperature. Another possible source of data reduction error is conversion from one set of engineering (e.g., SI) to another (e.g., English). This engineering unit conversion error is a bias and does not cancel when a difference is taken because the absolute bias is different at different temperatures. Truncation and roundoff errors in modern digital data acquisition systems are usually negligible, therefore, they will be neglected.

\section{Uncertainty of Temperature Difference}

To estimate the error or uncertainty of the probe the experimental data will be presented as a temperature difference $T^{p}-T^{T}$. Assuming $T^{r}$ (i.e., the reference temperature) is the true wall temperature, one has a direct measure of the probe error. Unfortunately, both 
the probe $\left(\mathrm{T}^{\mathrm{p}}\right)$ and reference $\left(\mathrm{T}^{\mathrm{r}}\right)$ temperatures have errors; one works to ensure that by use of proven mounting techniques and procedures, the reference temperature measurement error is much smaller than that of the probe and can be ignored.

The probe and reference temperatures may be expressed as the sum of the actual wall temperature $\mathrm{T}_{\mathrm{A}}$ and an uncertainty:

$\mathrm{T}^{\mathrm{p}}=\mathrm{T}_{\mathrm{A}}+\mathrm{U}_{\mathrm{t}}^{\mathrm{p}}$, and

$\mathrm{T}^{\mathrm{r}}=\mathrm{T}_{\mathrm{A}}+\mathrm{U}_{\mathrm{t}}$

where $U_{t}^{p}$, and $U_{t}$ are the total uncertainties of the probe and reference. Taking the difference one obtains the following:

$T^{p}-T^{r}=U^{p}-U_{t}^{r}$

From [3], one may express the total uncertainty of any measurement as follows:

$\mathrm{U}_{\mathrm{t}}= \pm[\mathrm{B}+\mathrm{tS}]$

where $U_{t}$ is the total error or uncertainty, $B$ is the bias, and $S$ is the random error, and $t$ is a statistical term called "Student's t." " $t$ " is a constant that varies depending on the number of samples taken; it is smaller for larger samples. Total uncertainty for the reference temperature can be expressed as the sum of the calibration, data acquisition, and data reduction uncertainties, as follows:

$\mathrm{U}_{\mathrm{t}}^{\mathrm{T}}=\mathrm{U}_{\mathrm{c}}^{\mathrm{r}}+\mathrm{U}_{\mathrm{da}}^{\mathrm{r}}+\mathrm{U}_{\mathrm{dr}}^{\mathrm{T}}$, where

$\mathrm{U}_{\mathrm{c}}^{\mathrm{r}}= \pm\left[\mathrm{B}_{\mathrm{c}}^{\mathrm{r}}+\mathrm{t} \mathrm{S}_{\mathrm{c}}^{\mathrm{r}}\right]$

$\mathrm{U}_{\mathrm{da}}^{\mathrm{r}}= \pm\left[\mathrm{B}_{\mathrm{da}}^{\mathrm{r}}+\mathrm{tS}_{\mathrm{da}}^{\mathrm{r}}\right]$

$\mathrm{U}_{\mathrm{dr}}^{\mathrm{r}}= \pm\left[\mathrm{B}_{\mathrm{dr}}^{\mathrm{r}}+\mathrm{tS}_{\mathrm{dr}}^{\mathrm{r}}\right]$

where the subscripts ' $c$ ', 'da', and 'dr' refer to 'calibration,' 'data acquisition,' and 'data reduction,' the superscript ' $r$ ' refers to the 'reference' thermocouple and the subscript ' $t$ ' the total uncertainty.

Similarly, for the probe:

$\mathrm{U}_{\mathrm{t}}^{\mathrm{P}}=\mathrm{U}_{\mathrm{c}}^{\mathrm{p}}+\mathrm{U}_{\mathrm{da}}^{\mathrm{p}}+\mathrm{U}_{\mathrm{dr}}^{\mathrm{p}}$

$\mathrm{U}_{\mathrm{c}}^{\mathrm{p}}= \pm\left[\mathrm{B}_{\mathrm{c}}^{\mathrm{p}}+\mathrm{t} \mathrm{S}_{\mathrm{c}}^{\mathrm{p}}\right]$

$\mathrm{U}_{\mathrm{da}}^{\mathrm{p}}= \pm\left[\mathrm{B}_{\mathrm{da}}^{\mathrm{p}}+\mathrm{tS}_{\mathrm{da}}^{\mathrm{p}}\right]$ 
$\mathrm{U}_{\mathrm{dr}}^{\mathrm{p}}= \pm\left[\mathrm{B}_{\mathrm{dr}}^{\mathrm{p}}+\mathrm{t} \mathrm{S}_{\mathrm{dr}}^{\mathrm{p}}\right]$

Taking the difference between these two uncertainties one obtains the following:

$U_{t}^{P}-U_{t}^{T}=\left(U_{c}^{P}-U_{c}^{T}\right)+\left(U_{d a}^{P}-U_{d a}^{T}\right)+\left(U_{d r}^{P}-U_{d r}^{T}\right)$

One may be tempted to say the differences $U_{c}^{p}-U_{c}^{T}$ and $U_{d r}^{p}-U_{d r}^{T}$ are zero; unfortunately this is not necessarily the case. Assuming both the reference thermocouples and probes were calibrated using the same equipment and thermocouple wire, the biases have been minimized in the calibration process. The differences are not zero unless the reference thermocouple and probe temperatures are the same; this is because for thermocouples there is no guarantee that the calibration bias is constant with temperature. Similar arguments hold for the data reduction category $\left(\mathrm{U}_{\mathrm{dr}}^{\mathrm{p}}-\mathrm{U}_{\mathrm{dr}}^{\mathrm{T}}\right)$. With proper voltage to temperature conversion equations and engineering unit conversion these biases can be minimized but the difference is not necessarily zero, also because the probe and reference temperatures are not the same. However, with careful calibration and data reduction techniques the uncertainty differences $U_{c}^{p}-U_{c}^{T}$ and $U_{d r}^{p}-U_{d r}$ can be made small. We will assume this is the case, i.e., $\mathrm{U}_{\mathrm{c}}^{\mathrm{p}}-\mathrm{U}_{\mathrm{c}}^{\mathrm{r}}$ and $\mathrm{U}_{\mathrm{dr}}^{\mathrm{p}}-\mathrm{U}_{\mathrm{dr}}^{\mathrm{d}}$ are negligible compared with $\mathrm{U}_{\mathrm{da}}^{\mathrm{p}}$ $-U_{\mathrm{da}}^{\mathrm{r}}$.

The data acquisition uncertainty is composed of the following parts:

$\mathrm{U}_{\mathrm{da}}^{\mathrm{p}}=\mathrm{U}_{\mathrm{dash}}^{\mathrm{p}}+\mathrm{U}_{\mathrm{mm}}^{\mathrm{p}}+\mathrm{U}_{\mathrm{ee}}^{\mathrm{p}}+\mathrm{U}_{\mathrm{sa}}^{\mathrm{p}}+\mathrm{U}_{\mathrm{p}}^{\mathrm{p}}$

where,

$\mathrm{U}_{\text {dash }}=$ data acquisition system software and hardware errors (e.g., those from the digital voltmeter),

$\mathrm{U}_{\mathrm{mm}}^{\mathrm{P}} \quad$ = mounting method errors (see below for more details)

$\mathrm{U}_{\mathrm{ee}} \quad=$ environmental effects on transducer errors, (i.e, temperature and humidity limits, etc.) not taken account in the calibration process,

$\mathrm{U}_{\mathrm{sa}}^{\mathrm{p}} \quad$ = spacial averaging errors (i.e., probe and reference measure an "average" temperature over the contact area of the measuring junction of the thermocouple), and,

$\mathrm{U}_{\mathrm{p}}^{\mathrm{p}} \quad=$ position errors (different locations for probe and reference thermocouple).

For the purposes of this analysis, it will be assumed that $U_{\text {dash }}^{\mathrm{p}}, \mathrm{U}^{\mathrm{p}}{ }_{\mathrm{ee}}$, and $\mathrm{U}_{\mathrm{sa}}^{\mathrm{p}}$, are identical for both the probe and reference thermocouple and so cancel in the subtraction.

It is also assumed that there are minimal position errors $U_{p}^{p}$ (although for large temperature gradients on the wall surface this may not be a good assumption), so $U_{p}^{p}$ is the same for both. Therefore, for the data acquisition category of the error, $\mathrm{U}_{\mathrm{da}}^{\mathrm{p}}$, the remaining part (and the one of most interest) is the term $\mathrm{U}_{\mathrm{mm}}^{\mathrm{p}}-\mathrm{U}_{\mathrm{mm}}^{\mathrm{r}}$. It is this term that can generate a significant portion of the total error (often the single largest portion), and the one that can be affected most by a proper probe design. 
The mounting method error has a number of components. One source is from conduction along the thermocouple wires, a second is from less than perfect thermal contact between the probe and surface (i.e., thermal contact resistance), and a third is due to different dynamic responses of the probe and reference thermocouple to the radiative flux from the heaters and natural convection effects.

These errors are present in both the probe and reference thermocouple. However, with careful mounting, these errors can be minimized in the reference thermocouple. Such is not the case with the probe; all three mounting method errors are potentially significant. Therefore, with mounting method errors minimized in the reference thermocouple, the major portion of the remaining error in the data acquisition category is the mounting method error for the probe, $\mathrm{U}^{\mathrm{p}}{ }_{\mathrm{mm}}$.

Referring to equation $\{6\}$, the biggest contributor to the total uncertainty difference is that due to data acquisition category, and the largest contributor to the total data acquisition error is that from the mounting method. Therefore, the temperature difference $T^{p}-T^{r}$ is a good measure of the probe mounting method error.

When making modifications to the probe design, at some point the mounting method errors are reduced to the level of other errors, e.g., calibration and data reduction, therefore, further attempts at error reduction via the probe design alone are not warranted without a corresponding look at the other error sources. For example, "standard" Type K (chromel-alumel) thermocouple wire errors are quoted as $\pm 4^{\circ} \mathrm{F}$ between $32-530^{\circ} \mathrm{F}$ and $\pm 0.75 \%$ of the reading between $530-2300^{\circ} \mathrm{F}$ [5] - this is an error of the calibration type. At $870^{\circ} \mathrm{F}, 0.75 \%$ is about $6.5^{\circ} \mathrm{F}$. For a typical data acquisition system used at Sandia for thermocouple measurements, the stated error is about $\pm 2.5^{\circ} \mathrm{F}$ over the range of temperature including $870^{\circ} \mathrm{F}$. This error is of the data acquisition category. A typical voltage to temperature conversion for Type $\mathrm{K}$ thermocouples used at Sandia has an error of about $0.5^{\circ} \mathrm{C}$ over the entire temperature range [6]. This is a data reduction error. Summing just these three error sources, one obtains about $\pm 1 \%$ at $870^{\circ} \mathrm{F}$. Therefore, when the probe design has been optimized to within (say) about $1 \%$ (as the Russian probe has), then one may not be able to distinguish the error source (unless there is an unmistakable bias offset to the data).

In summary, assuming the calibration and data reduction errors are in the $1 \%$ range (this should be checked by summing all the potential error sources, not just the three listed in the previous paragraph), one can postulate that biases greater than about $1 \%$ are due to the mounting method, and one should try to reduce these errors via proper probe design.

\section{RESULTS OF EXPERIMENTS WITH RUSSIAN PROBE}

Figures 2-5 show results of the Russian probes using a heat-up rate of $15^{\circ} \mathrm{C} / \mathrm{hr}\left(27^{\circ} \mathrm{F} / \mathrm{hr}\right)$. As can be seen in Figures 2 and 3, the wall section temperature is relatively linear from 


\section{Performance Testing the Russian RPV Temperature Measurement Probe}

the beginning of the test to about the 24 hour time. (The heat-up rate was purposely slowed between 24-28 hours.) The linear heat-up is as expected because the control system was programmed to provide a linear rise of $15^{\circ} \mathrm{C} / \mathrm{hr}$. The probes (TC3 and TC6) rise above the wall section temperature (TC1 and TC4) at the beginning of the heat-up, and slowly approach their companion thermocouples (TCs) as the wall section reaches the annealing temperature.

Figures 4 and 5 show plots of the temperature difference $\left(T_{\text {probe }}-T_{\text {ref }}\right)$. As discussed in the previous section, this may be interpreted as a measure of the probe error assuming that the temperature $T_{\text {ref }}$ is an accurate representation of the wall temperature. As can be seen, the error rises quickly at the beginning of the heat-up to a maximum of about $27^{\circ} \mathrm{C}\left(49^{\circ} \mathrm{F}\right)$ (Figure 5), then decreases in an exponential-like shape to the beginning of the constant temperature portion at $470^{\circ} \mathrm{C}\left(878^{\circ} \mathrm{F}\right)$. At the beginning of the constant temperature portion (hour 32-33), the temperature difference drops quickly from about a plus $2-3^{\circ} \mathrm{C}$ $\left(4-5^{\circ} \mathrm{F}\right)$ to a minus $2-3^{\circ} \mathrm{C}$. During the cool-down the error again rises to a maximum (negative value) then drops. Because the behavior of the errors are similar but opposite between the heat-up and cool-down, we will not discuss the cool-down further.

In general, the Russian probe design performed very well during the constant temperature portion, the probe is only about $2-3^{\circ} \mathrm{C}\left(4-5^{\circ} \mathrm{F}\right)(0.6 \%)$ in error. During the heat-up and cool-down, the probes are in error to a larger degree, but the absolute temperatures are lower and the overall accuracy is less critical.

Similar experiments with a higher $\left(28^{\circ} \mathrm{C} / \mathrm{hr}\right.$ or $\left.50^{\circ} \mathrm{F} / \mathrm{hr}\right)$ and lower $\left(10^{\circ} \mathrm{C} / \mathrm{hr}\right.$ or $\left.18^{\circ} \mathrm{F} / \mathrm{hr}\right)$ temperature heat-up rate were also performed by CNIITMASH. Qualitatively, the results were the same. (Figures showing these results are not presented here.) Quantitatively, errors during the heat-up were larger $\left(36^{\circ} \mathrm{C}\right.$ or $\left.65^{\circ} \mathrm{F}\right)$ for the $28^{\circ} \mathrm{C} / \mathrm{hr}\left(50^{\circ} \mathrm{F} / \mathrm{hr}\right)$ heat-up rate, and smaller $\left(17^{\circ} \mathrm{C}\right.$ or $\left.31^{\circ} \mathrm{F}\right)$ for the $10^{\circ} \mathrm{C} / \mathrm{hr}\left(18^{\circ} \mathrm{F} / \mathrm{hr}\right)$ heat-up rate. During the constant temperature portion, the errors were about $3^{\circ} \mathrm{C}\left(5^{\circ} \mathrm{F}\right)$ for the $\left(28^{\circ} \mathrm{C} / \mathrm{hr}\right.$ or $\left.50^{\circ} \mathrm{F} / \mathrm{hr}\right)$ heat-up rate and about $1^{\circ} \mathrm{C}\left(1.8^{\circ} \mathrm{F}\right)$ for the $\left(10^{\circ} \mathrm{C} / \mathrm{hr}\right.$ or $\left.18^{\circ} \mathrm{F} / \mathrm{hr}\right)$ heat-up rate. Since the heat-up rate has no lasting effect on the error during the constant temperature portion, the errors for all three experiments at $470^{\circ} \mathrm{C}\left(878^{\circ} \mathrm{F}\right)$ should be the same. This is the case for the 15 and $10^{\circ} \mathrm{C} / \mathrm{hr}$ rates $\left(-3^{\circ} \mathrm{C}\right)$, but the error is $+1^{\circ} \mathrm{C}$ for the $28^{\circ} \mathrm{C} / \mathrm{hr}$ rate.

Because in an actual anneal the probes would be located in an actual RPV and full size heater, rather than the smaller experimental setups, it would be beneficial to test the probe design in a larger test setup. Different results may be obtained. Different results may be due to issues such as different configuration factors between the probe and wall and probe and heaters in the real case. However, due to the requirement of larger wall sections and larger heater banks (and therefore greater costs), it was not possible to perform such tests. It was planned to perform several of these checks during the actual anneal at Midland.

Select results from the Sandia experiments [2] are shown in Figures 6-9. As can be seen in Figure 6, there is qualitative agreement between the probe responses (PR11, PR17, and 
PR22) and the probe responses in Figures 2 and 3. However, the magnitude of the errors in Figure 6 are much higher. Figures 7-9 show temperature differences between the wall and probe temperatures $\left(T_{w}-T_{p}\right)$; they are negative because the temperature difference is defined opposite to those in Figures 4 and 5. Again, qualitatively the plots are similar to the Russian results in Figures 4 and 5, but the error magnitudes are much more in the Sandia experiments. Errors are smaller because the Russian design is better than that described in [1]. Further discussion of Figures 7-9 will follow in the next section.

\section{RESULTS OF MODEL PREDICTIONS}

In [2], Gill, et.al developed a thermal model for the probe response based on an energy balance using only radiation heat transfer (conduction and convection were neglected). As shown in [2], for those cases where the model most closely represented the probe shape, the corrected probe response (using model predictions) was much closer to the actual wall temperature (i.e., the reference temperature).

The model was rearranged to predict the probe response as a function of a linearly increasing wall section temperature of $15^{\circ} \mathrm{C} / \mathrm{hr}\left(27^{\circ} \mathrm{F} / \mathrm{hr}\right)$. By modifying equation $\{12\}$ from [2], the difference equation used to predict the probe temperature is as follows:

$T_{p}(t+d t)=T_{p}(t)+\left(k_{2} / k_{1}\right)\left[T_{w}(t+d t)-T_{w}(t)\right]+\left(d t / k_{1}\right)\left[T_{w}(t)^{4}-T_{p}(t)^{4}\right]$,

with $\mathrm{k}_{2}=\left(2-\mathrm{e}_{\mathrm{w}}\right) * \mathrm{rho}_{\mathrm{w}}{ }^{*} \mathrm{c}_{\mathrm{w}}{ }^{*} \mathrm{~L}_{\mathrm{w}} / 2 * \operatorname{sigma}^{*} \mathrm{e}_{\mathrm{w}}$

and $\mathrm{k}_{\mathrm{l}}=\mathrm{rho}_{\mathrm{p}}{ }^{*} \mathrm{c}_{\mathrm{p}}{ }^{*} \mathrm{D}_{\mathrm{p}} / 6{ }^{*}$ sigma $^{*} \mathrm{e}_{\mathrm{p}}$

where, $e_{w}=$ wall section emissivity $=0.85, e_{p}=$ probe emissivity $=0.2$, sigma $=$ StefanBolzman's constant, $0.1712 \mathrm{E}-8 \mathrm{Btu} / \mathrm{hr} / \mathrm{ft}^{2} /{ }^{\circ} \mathrm{R}^{4}, \mathrm{D}_{\mathrm{p}}=$ probe diameter $(0.75 \mathrm{in}), \mathrm{L}_{\mathrm{w}}=$ wall section thickness $=6.75$ in (Sandia experiments), $c_{w}$ and $c_{p}$ are specific heats of wall and probe, hho $_{\mathrm{w}}$ and rho $\mathrm{p}_{\mathrm{p}}$ are the densities of the wall and probe, and dt is the time increment ( 0.1 hour)(A $0.2 \mathrm{hr}$ time increment was also used; the difference in the results were negligible). Because the wall section was being heated at a known rate (e.g., $15^{\circ} \mathrm{C} / \mathrm{hr}$ or $\left.27^{\circ} \mathrm{F} / \mathrm{hr}\right), \mathrm{T}_{\mathrm{w}}(\mathrm{t}+\mathrm{dt})$ was known in equation $\{8\}$, and because all other entries were either constants or values at the previous time, equation $\{8\}$ could be solved for the probe temperature at the next time step. Using typical values for the properties for a steel probe, $\mathrm{k}_{2} / \mathrm{k}_{1}=7.3$, and $\mathrm{d} t / \mathrm{k}_{1}=3.1 \mathrm{E}-11$.

Model predictions are shown in Figures 10-13. Figures 10 and 11 show the wall section temperature and the probe temperature, and Figures 12 and 13 show temperature differences (i.e., the error $T_{\text {probe }}-T_{\text {wall }}$ ). Figures 10 and 12 are for a probe emissivity of 0.2 and probe diameter of 0,75 in and Figures 11 and 13 are for a probe emissivity of 0.1 and probe diameter of $0.75 \mathrm{in}$. 
In Figure 10 the probe temperature rises faster than the wall section at the beginning of the heat-up, then slowly approaches the wall section temperature as the heat-up progresses. This pattern is similar to the responses shown in Figures 2 and 3 for the Russian probes. Recalling that the constant $k_{2} / k_{1}$ in equation $\{8\}$ was about 7.3 , and noting the behavior of the model at low temperatures is dominated by the first term in equation $\{8\}$, it is understandable that the model predicts a large difference between the probe and wall section at low temperatures. The predicted response shown in Figure 11 is similar to that in Figure 10, but with a smaller error.

The predicted errors in Figures 12 and 13 are qualitatively similar to the experimental probe responses shown in Figures 4 and 5. The errors in Figures 12 and 13 rise rapidly at the beginning of the experiment to a maximum, then have an exponential-like decay until the constant temperature portion is reached at 30 hours. At the beginning of the constant temperature portion, the temperature drops rapidly to zero. As shown Figure 12 and 13, the maximum errors predicted from the model are much larger $\left(110^{\circ} \mathrm{C}\right.$ or $198^{\circ} \mathrm{F}$ in Figure 12 and $83^{\circ} \mathrm{C}$ or $150^{\circ} \mathrm{F}$ in Figure 13) than those in Figures 4 and $5\left(22^{\circ} \mathrm{C}\right.$ or $40^{\circ} \mathrm{F}$ in Figure 4 and $27^{\circ} \mathrm{C}$ or $49^{\circ} \mathrm{F}$ in Figure 5).

During the constant temperature portion, the predicted errors are zero (see Figures 12 and 13). This is so because heat transfer by convection and conduction are not included in the model. Using generally accepted correlations for the convective heat transfer from a vertical wall (RPV wall section) and a sphere (probe), it can be shown that under the same conditions, the convective heat transfer coefficient (h) is a factor of 2-4 larger for a sphere the size of the probe ( 0.75 in diameter from Sandia experiments) as compared to the convective heat transfer coefficient for a vertical flat plate. Therefore, the probe will cool faster than the wall section, and the probe temperature will drop below that of the wall during the constant temperature portion. This behavior can be seen in Figures 4 and 5 and in many of the Sandia probes (e.g., Figure 8).

Therefore, the model qualitatively predicts the general characteristics of the probe response, although the actual Russian probe errors are about much less (e.g., 1/4 to 1/3) than the predicted errors.

\section{USING THE MODEL TO IMPROVE THE PROBE DESIGN}

The model may be used to optimize the probe design to produce more accurate measurements. Noting as above that the early time response is dependent on the first term in equation $\{8\}$ and therefore the ratio $\mathrm{k}_{2} / \mathrm{k}_{1}$, one can modify parameters of the probe design to reduce the errors at early times.

One way to reduce the ratio $k_{2} / k_{1}$ is to reduce the probe emissivity $e_{p}$. Predictions when using the probe emissivity as 0.1 rather than 0.2 are shown in Figures 12 and 13. As can be seen by comparing Figures 12 and 13, the probe error was reduced from a maximum 
of about $110^{\circ} \mathrm{C}\left(198^{\circ} \mathrm{F}\right)$ to about $83^{\circ} \mathrm{C}\left(150^{\circ} \mathrm{F}\right)$ when the probe emissivity was reduced from 0.2 to 0.1 . This behavior is in agreement with the experimental results presented in [2], see for example Figure 7. In Figure 7 the probes with lower emissivity (PR11 and PR2) show smaller errors as compared to probes with higher emissivity (PR22 and PR3).

Another way to effect the probe error during the early times is to vary the product ' $\mathrm{rho}_{\mathrm{p}}{ }^{*} \mathrm{c}_{\mathrm{p}}$ ' (see definition of $\mathrm{k}_{1}$ ) Various metals can be employed to see if this product can be raised. Table 1 shows a summary of the rho ${ }_{\mathrm{p}}{ }^{*} \mathrm{c}_{\mathrm{p}}$ product for various metals. As can be seen, the variation is from a maximum of 57.2 for nickel to a minimum of 48.9 for brass, only about a $16 \%$ change. Therefore, based on this simple model, one would conclude that changing the probe material would reduce the probe errors, but not as much as one would desire since the change on the rho ${ }_{p}{ }^{*} c_{p}$ product by use of different materials is not as large as that obtained by reducing the emissivity. Reduction in the error during the heat-up portion is also confirmed from the results in [2] where, during the heat-up for all three experiments, the brass probes showed a smaller error than did the stainless steel probes. This behavior is shown in Figure 8, where the brass probes (PR25 and PR12) show smaller errors than the stainless steel probes (PR2 and PR11).

\begin{tabular}{|c|c|}
\hline Table 1:rho ${ }_{p}{ }^{*} c_{p}$ Product for Various Metals \\
\hline Metal & rho ${ }_{\mathrm{p}}{ }^{*} \mathrm{c}_{\mathrm{p}}$ product $\left(\mathrm{BTU} / \mathrm{ft}^{3 * \circ} \mathrm{F}\right)$ \\
\hline Brass & 48.9 \\
\hline Constantan & 55.7 \\
\hline Copper & 50.8 \\
\hline Mild steel & 53.9 \\
\hline Stainless steel & 53.7 \\
\hline Nickel & 57.2 \\
\hline
\end{tabular}

One can also increase the size of the probe, because, as can be seen from the definition of $k_{1}$, increasing $D_{p}$ increases $k_{1}$, thereby decreasing the ratio $k_{2} / k_{1}$. However, by increasing the size of the probe, the wall section will be shaded from the heaters, thereby disturbing the wall temperature. An important rule of measurement engineering is to disturb the surface you are measuring the least amount possible, and in this case a larger probe may disturb the wall temperature more. However, the probe size is very small as compared to the RPV, so the shading effect of increasing the probe size from say $3 / 4$ in to 1 in would likely be negligible. Figure 9 shows several cases that show the effect of probe diameter; in two of the three cases a larger probe diameter ( 1 in vs $3 / 4$ in) has smaller errors.

Although possible, it is likely not feasible or desirable to attempt to change the RPV wall properties. The one wall parameter that could be changed is the wall emissivity $e_{w}$. As can be seen from the definition of $k_{2}$, other parameters are fixed and therefore not variable. To make $\mathrm{k}_{2} / \mathrm{k}_{1}$ closer to 1.0 , one can increase $\mathrm{e}_{\mathrm{w} .}$. This would result in a smaller 
probe error at early times. However, this is not really feasible in the RPV in an operating plant.

\section{SUMMARY}

\section{Russian Probe Results}

From the data presented, results show the Russian probe design is accurate to within a maximum of about $27^{\circ} \mathrm{C}\left(49^{\circ} \mathrm{F}\right)$ during the early portions of the heat-up, much less than the Sandia results. During the constant temperature portion at $470^{\circ} \mathrm{C}\left(878^{\circ} \mathrm{F}\right)$, the probe errors were only about $2-3^{\circ} \mathrm{C}\left(4-5^{\circ} \mathrm{F}\right)$, or less than $1 \%$. Probe errors are larger for faster heat-up rates, and smaller for slower heat-up rates.

\section{Error Analysis}

An error analysis was performed on the temperature difference $T^{p}-T^{r}$. It was shown that this difference is a direct measure of the error due to the "mounting method" (i.e., the method by which the wall temperature is measured). The mounting method error can be large if the probe is poorly designed.

\section{Model Predictions}

The thermal model originally presented in [2] was modified to provide the predicted probe temperature given a fixed wall temperature rise rate (e.g., $15^{\circ} \mathrm{C} / \mathrm{hr}$ or $27^{\circ} \mathrm{F} / \mathrm{hr}$ ). Predictions agreed qualitatively with results of both the Sandia and Russian experiments, but predicted larger errors. Based on the qualitative agreements, an additional prediction was made to improve the design. The parameter of greatest interest is the probe emissivity; it is desirable to make this parameter as low as possible. Other parameters (e.g., probe material, size) could also be changed (larger rho* ${ }^{\mathrm{p}}$ product, larger probe diameter) to decrease the error.

\section{CONCLUSIONS}

1) Based on the data available, the Russian probe design is accurate (i.e., less than 1\%) during the constant temperature portion of the annealing procedure.

2) Based on the error analysis, the temperature difference $T^{p}-T^{T}$ is a direct measure of the error due to the different methods by which the probe and reference thermocouples measure the wall temperature. The error associated with the mounting method can be a large contributor to the total error if there is a poor probe design.

3) Based on model predictions, the thermal model provides a qualitative assessment of the probe response and may be used to improve the probe design. 


\section{REFERENCES}

[1] Cole, N.M., and T. Friderichs, 1991, "Report on the Annealing of the Novovoronezh Unit 3 Reactor Vessel in the USSR," U.S. Nuclear Regulatory Commission, NUREG/CR-5760, MPR Associates, Alexandria, VA.

[2] Acton, R.U., W. Gill, D.J. Sais, D.H. Schulze, and J.T. Nakos, “An Investigation of Temperature Measurement Methods in Nuclear Power Plant Reactor Pressure Vessel Annealing," Sandia Report SAND96-1179, May 1996.

[3] ANSU/ASME PTC 19.1-1985, "Measurement Uncertainty, Instruments and Apparatus," Supplement to ASME Performance Test Codes, Reaffirmed 1990.

[4] Dieck, Ronald H., Measurement Uncertainty, Methods and Applications, Second Edition, Instrument Society of America, 1997.

[5] ASTM STP 470B, Manual on the Use of Thermocouples in Temperature Measurement, American Society of Testing and Materials, 1981, pp 184.

[6] NBS Monograph 125, "Thermocouple Reference Tables Based on the IPS-68," U.S. Department of Commerce, National Bureau of Standards, Issued March 1974, page 384 . 


\section{Figure 1: Experimental Setup for Russian Experiments}

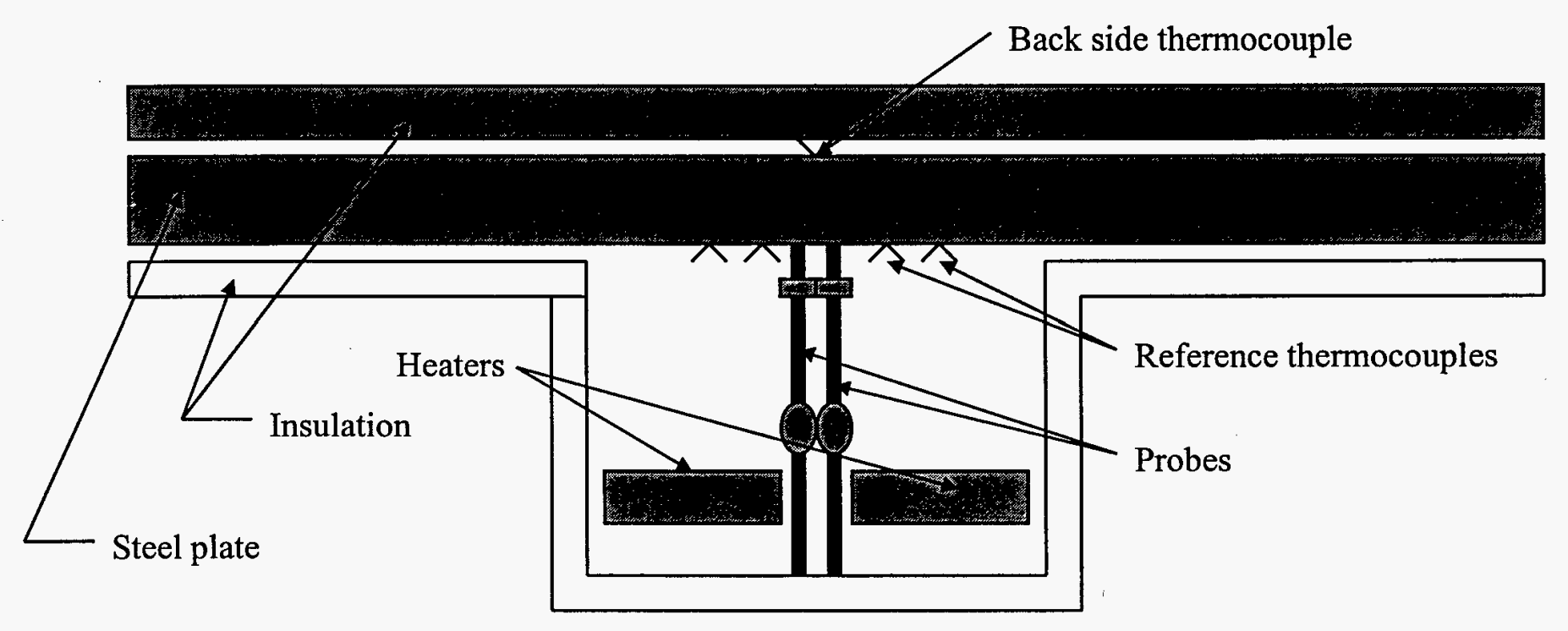




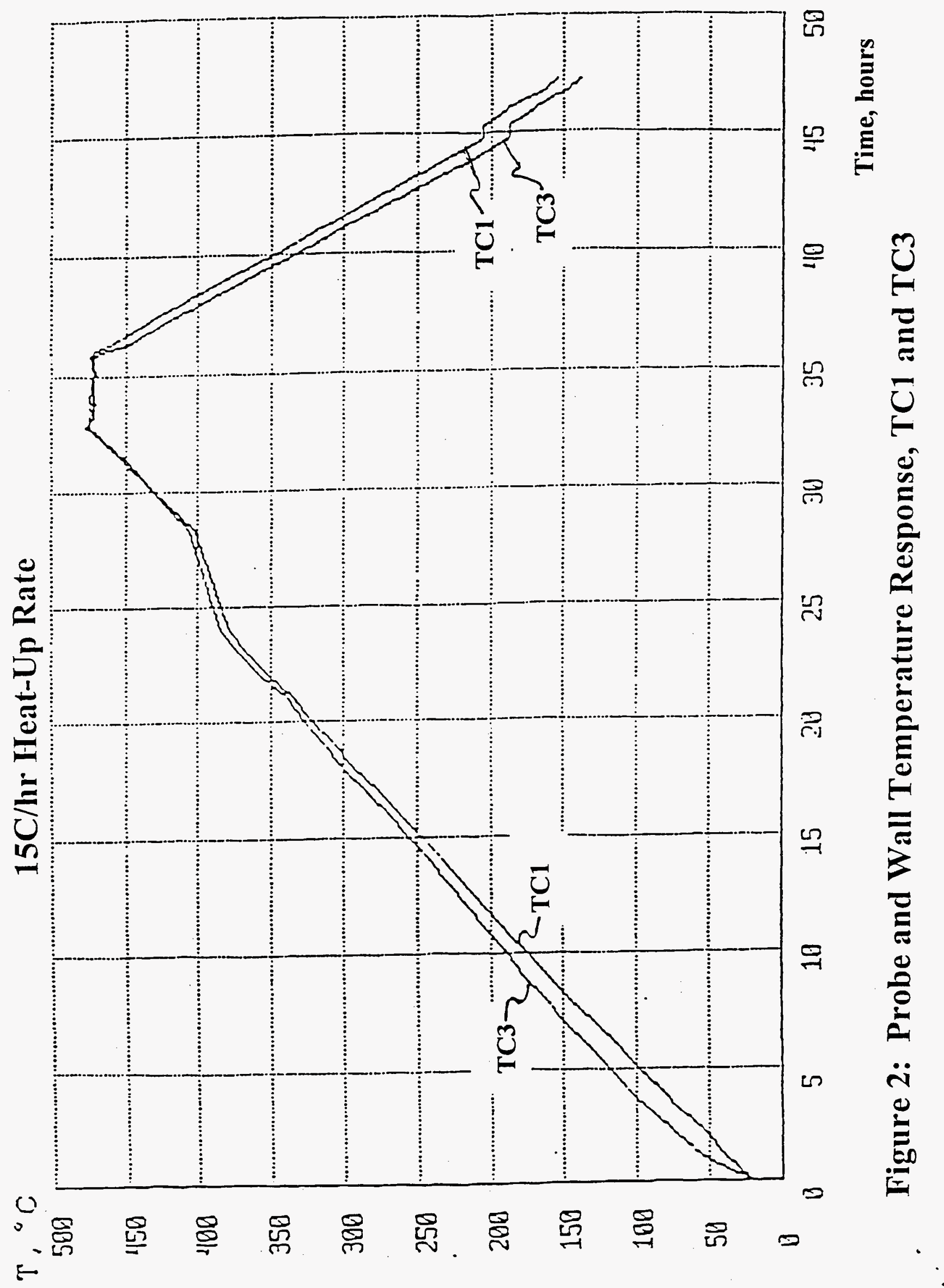




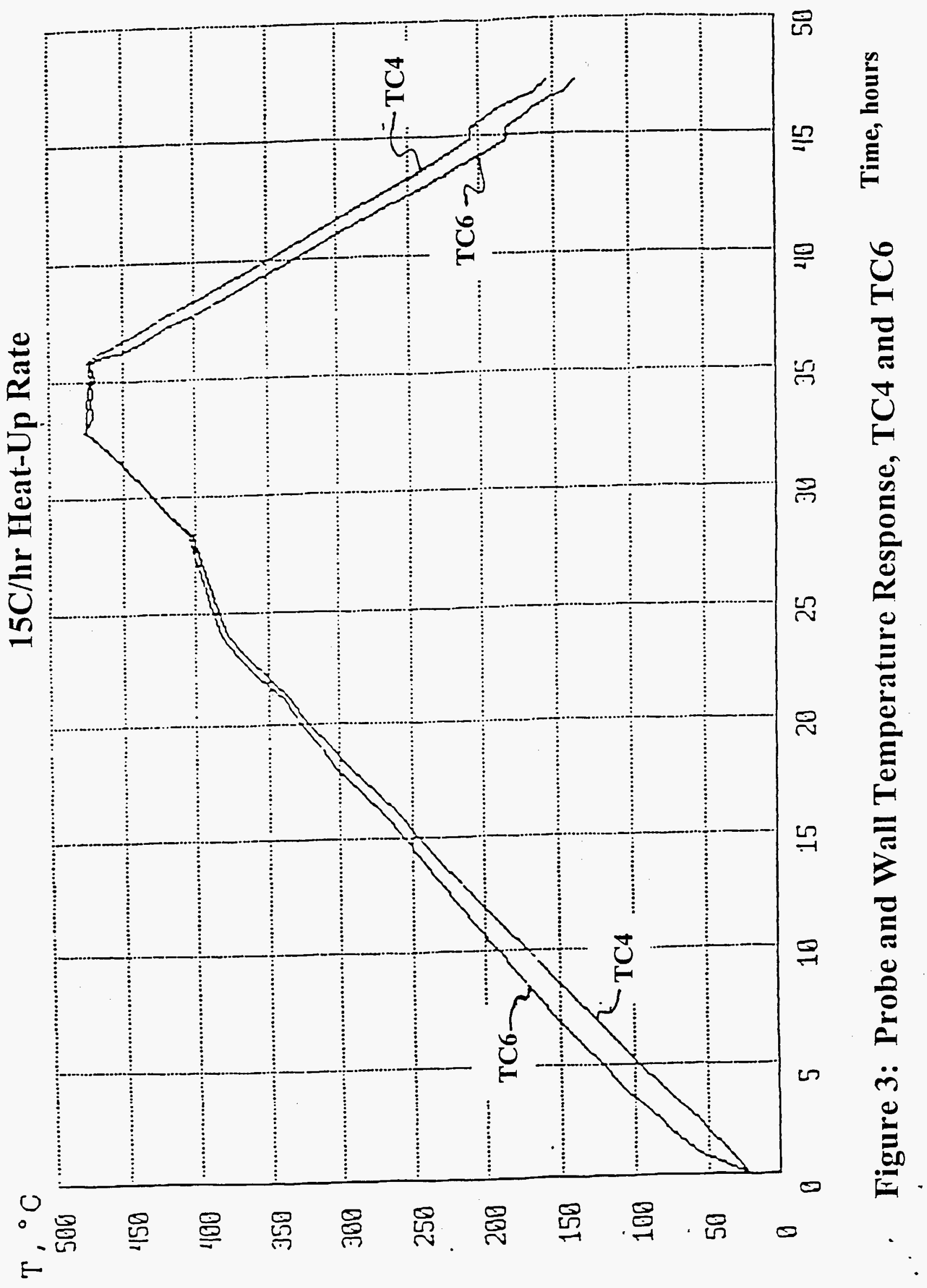




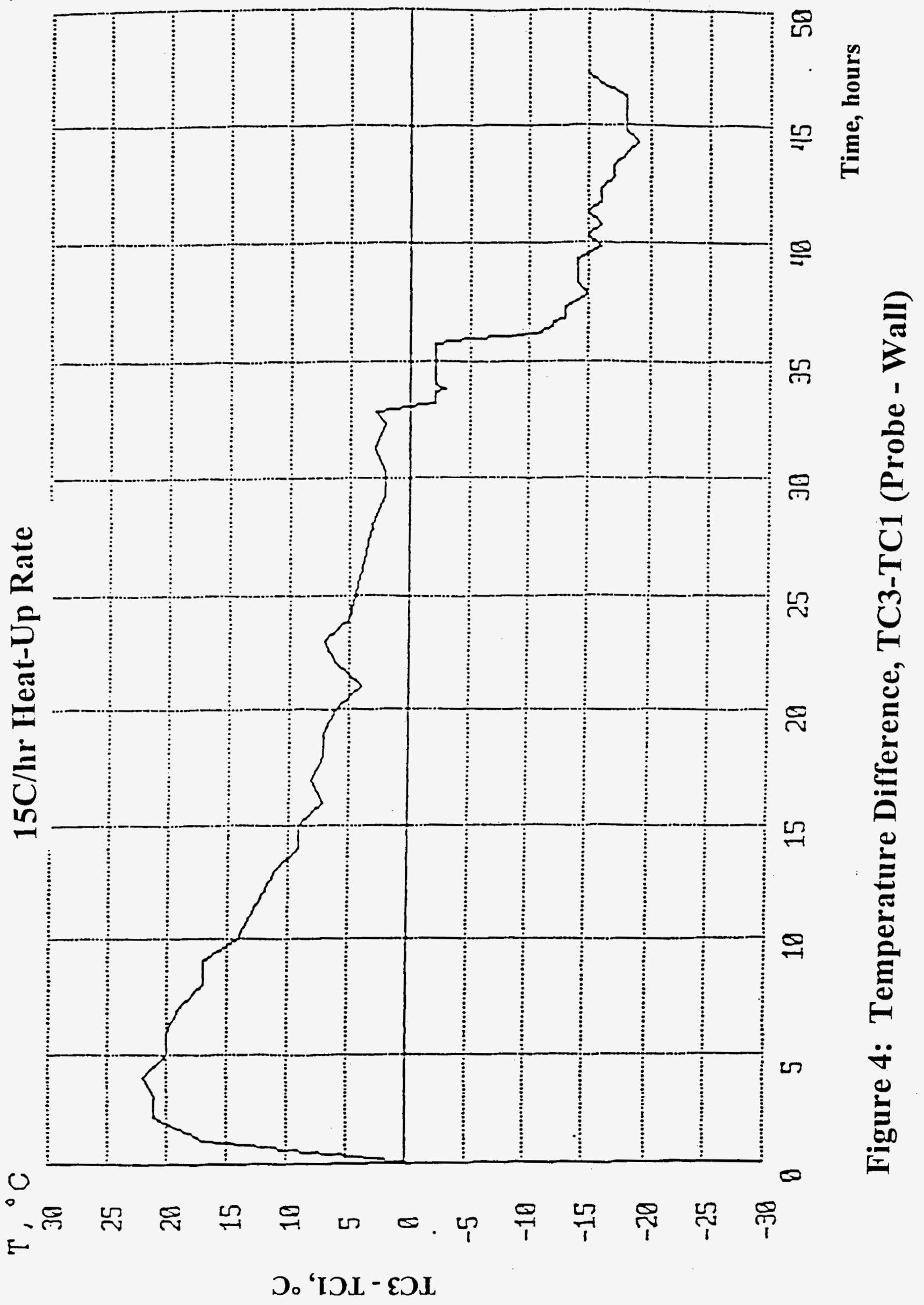




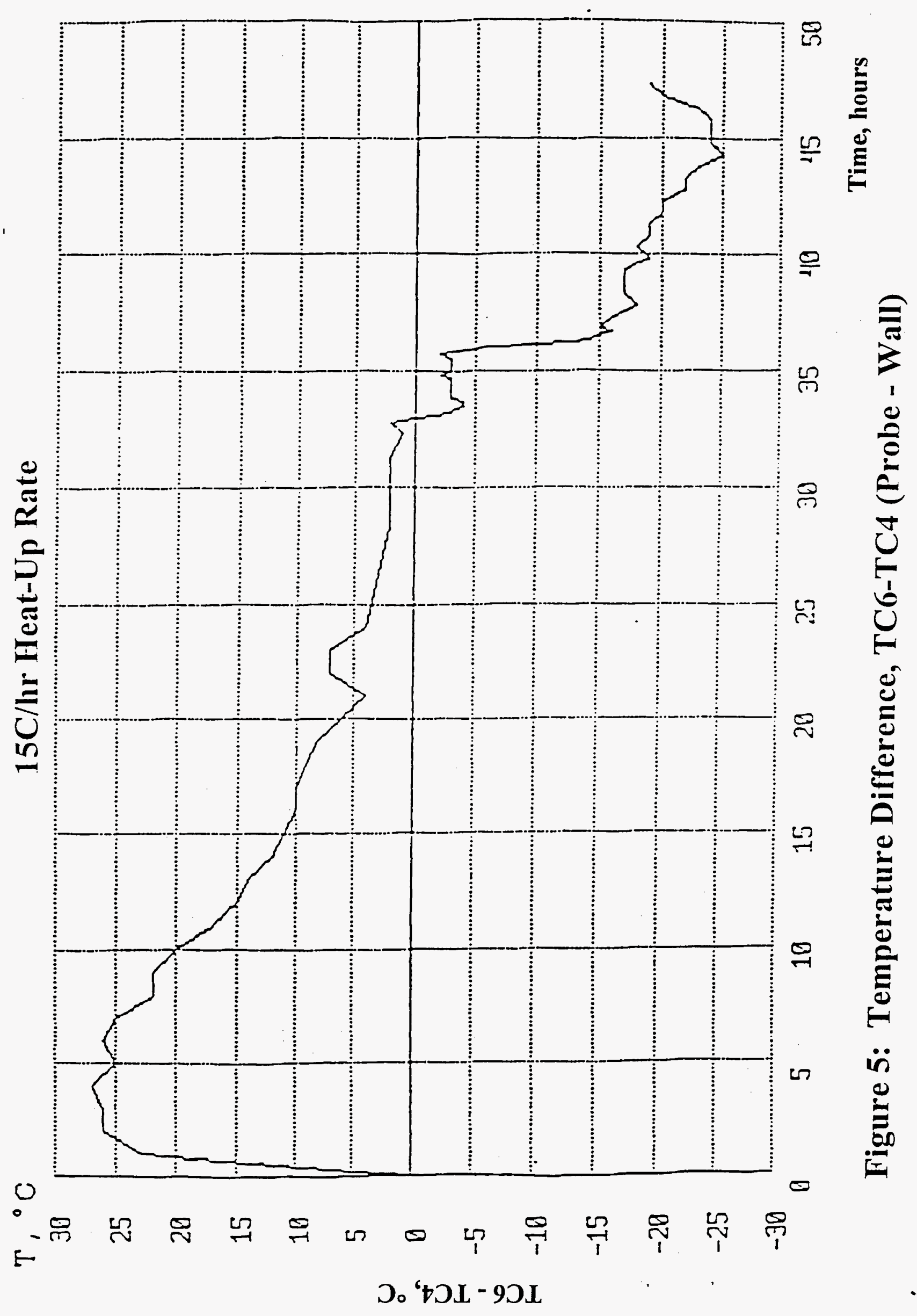




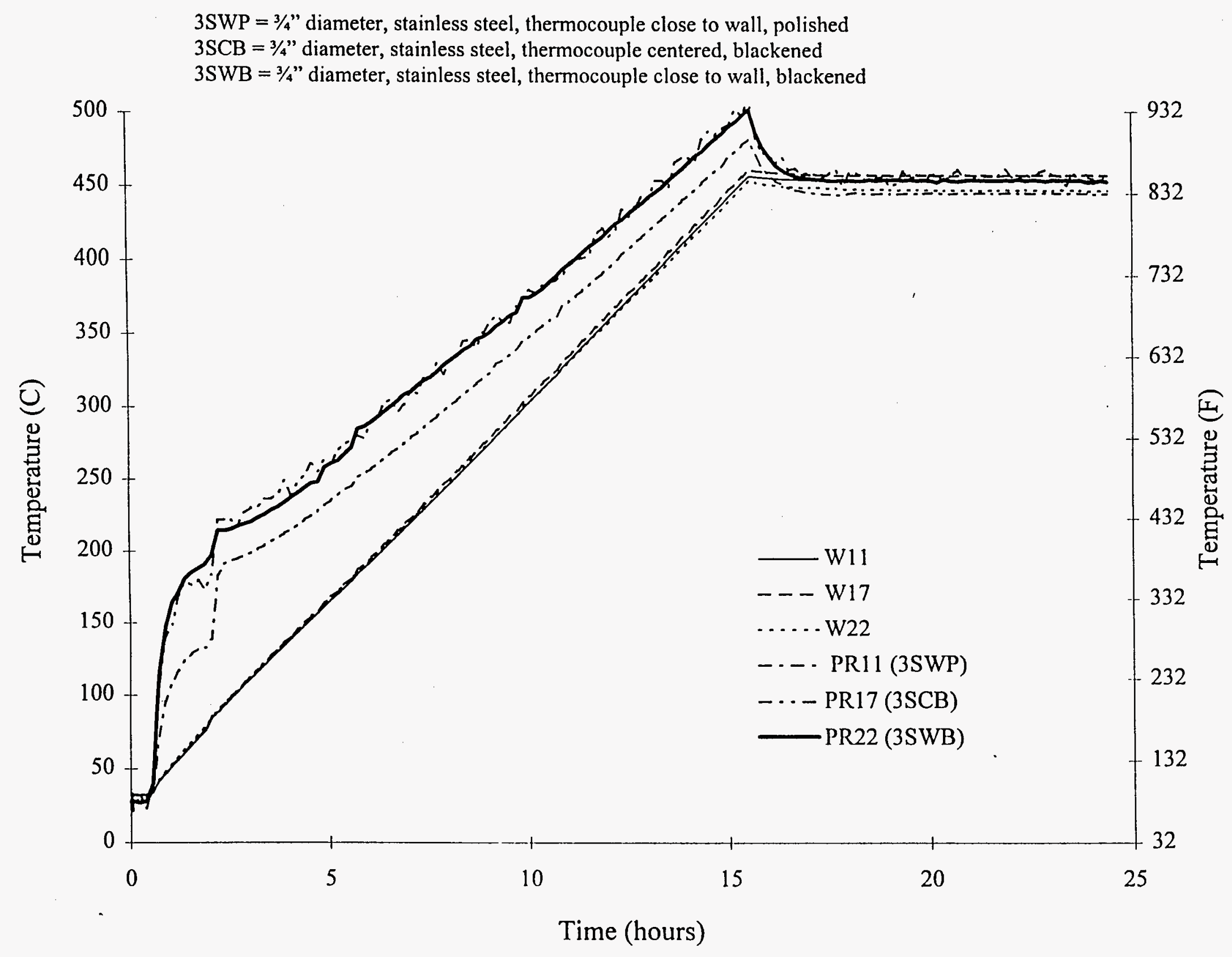

Figure 6 Test 1, Comparison of Wall TC and Probe Responses, 1.9-cm SS Probes. 


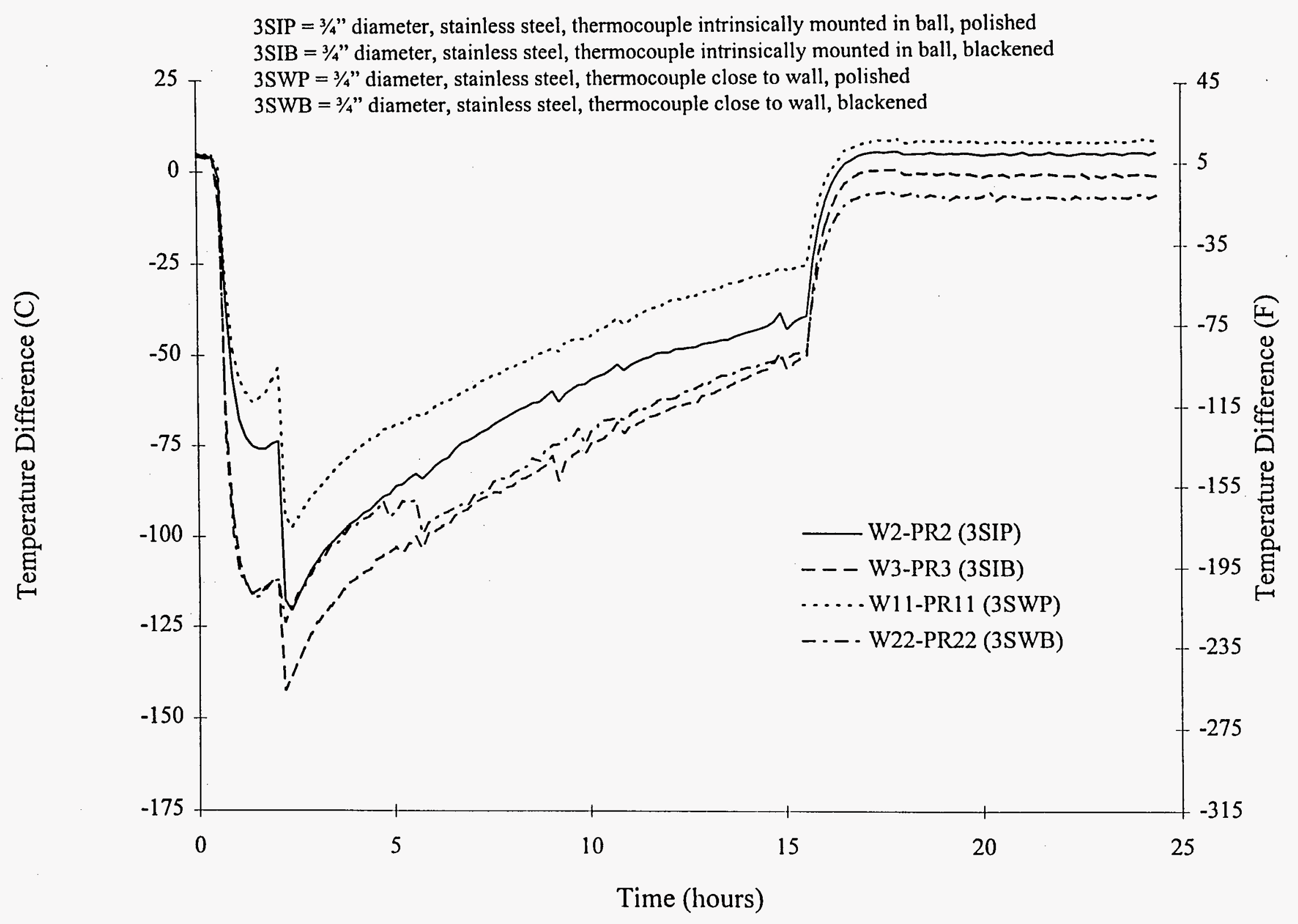

Figure 7 Test 1, Effect of Ball Emissivity on Errors, 1.9-cm SS Probes. 


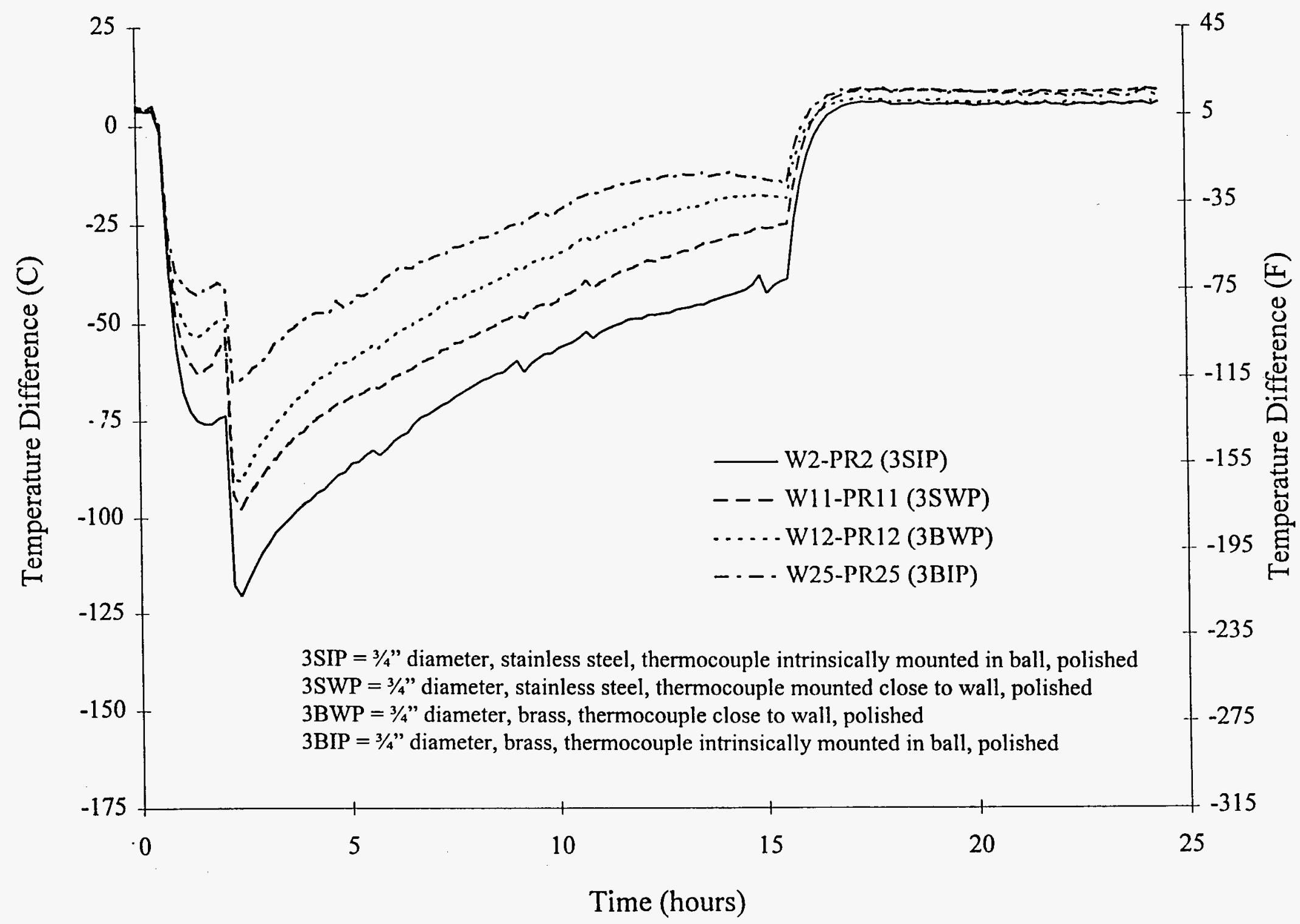

Figure 8 Test 1, Effect of Material on Errors, 1.9-cm SS and Brass Probes. 


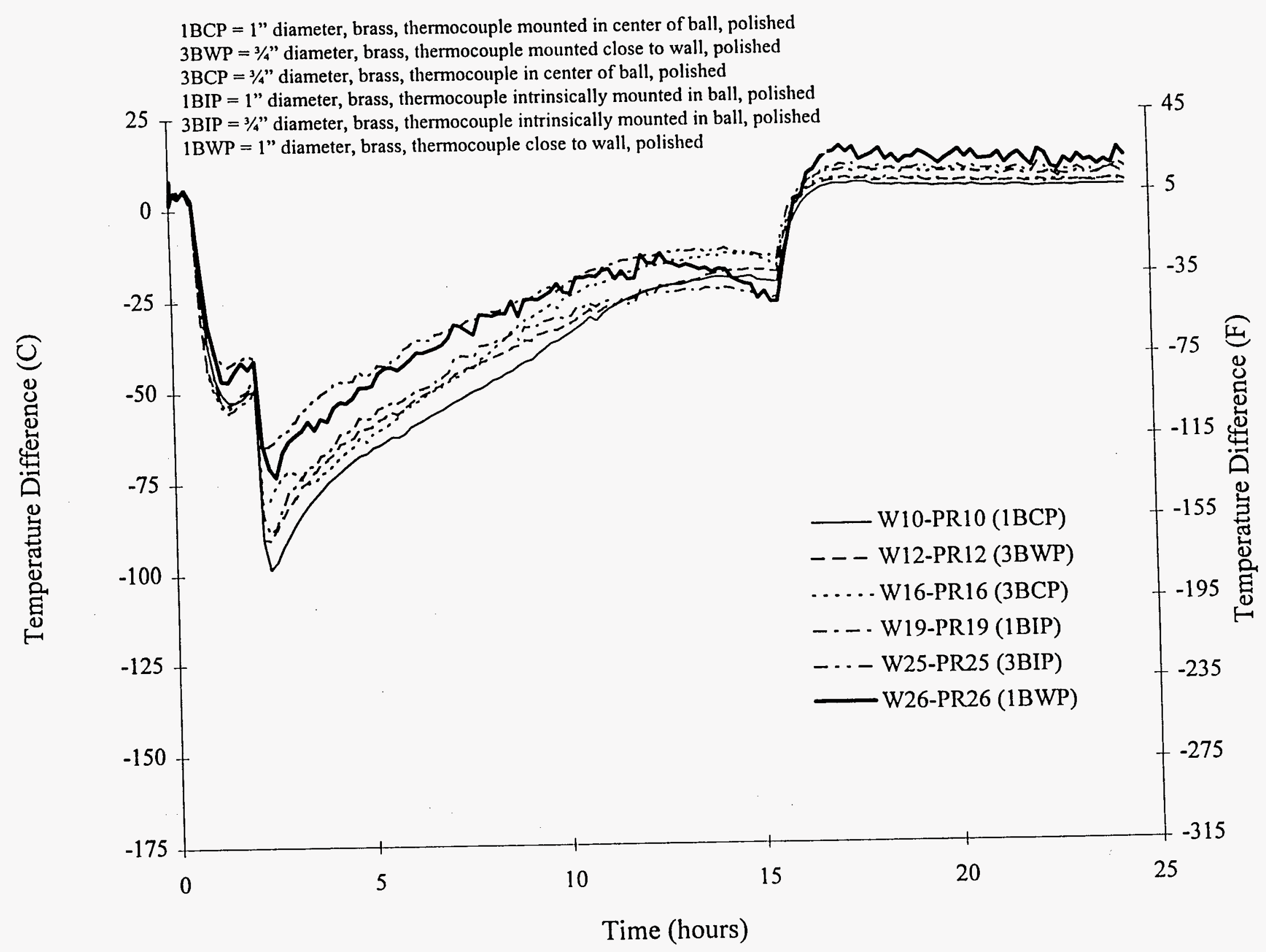

Figure 9 Test 1, Effect of Ball Size and Thermocouple Location on Errors, 1.9-cm and 2.5-cm Brass Probes. 
Predicted RPV Temperature Measurement Probe Response

Probe emissivity $=0.2$, probe diameter $=0.75 \mathrm{in}, 15 \mathrm{C} / \mathrm{hr}$ heat-up

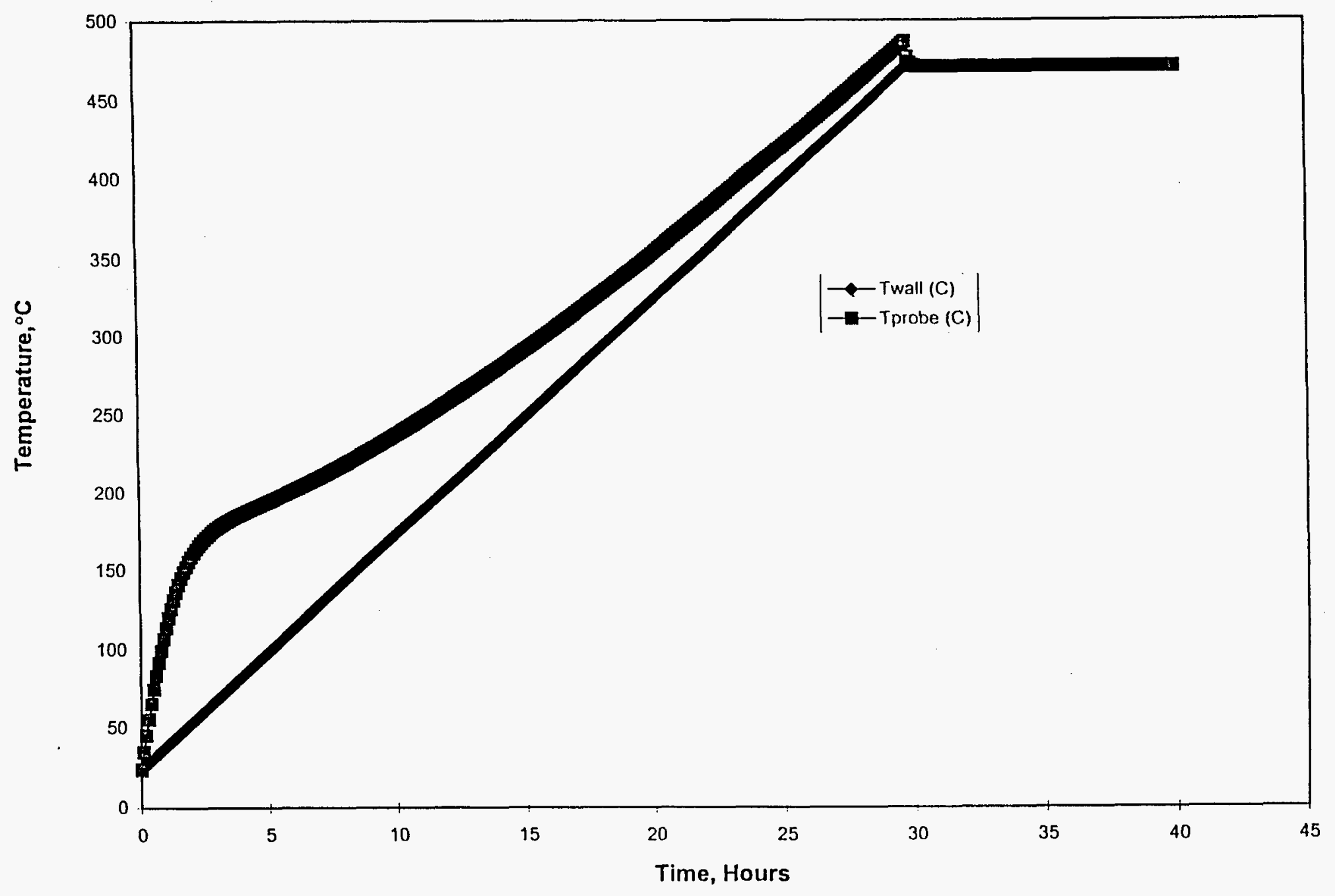

Figure 10 


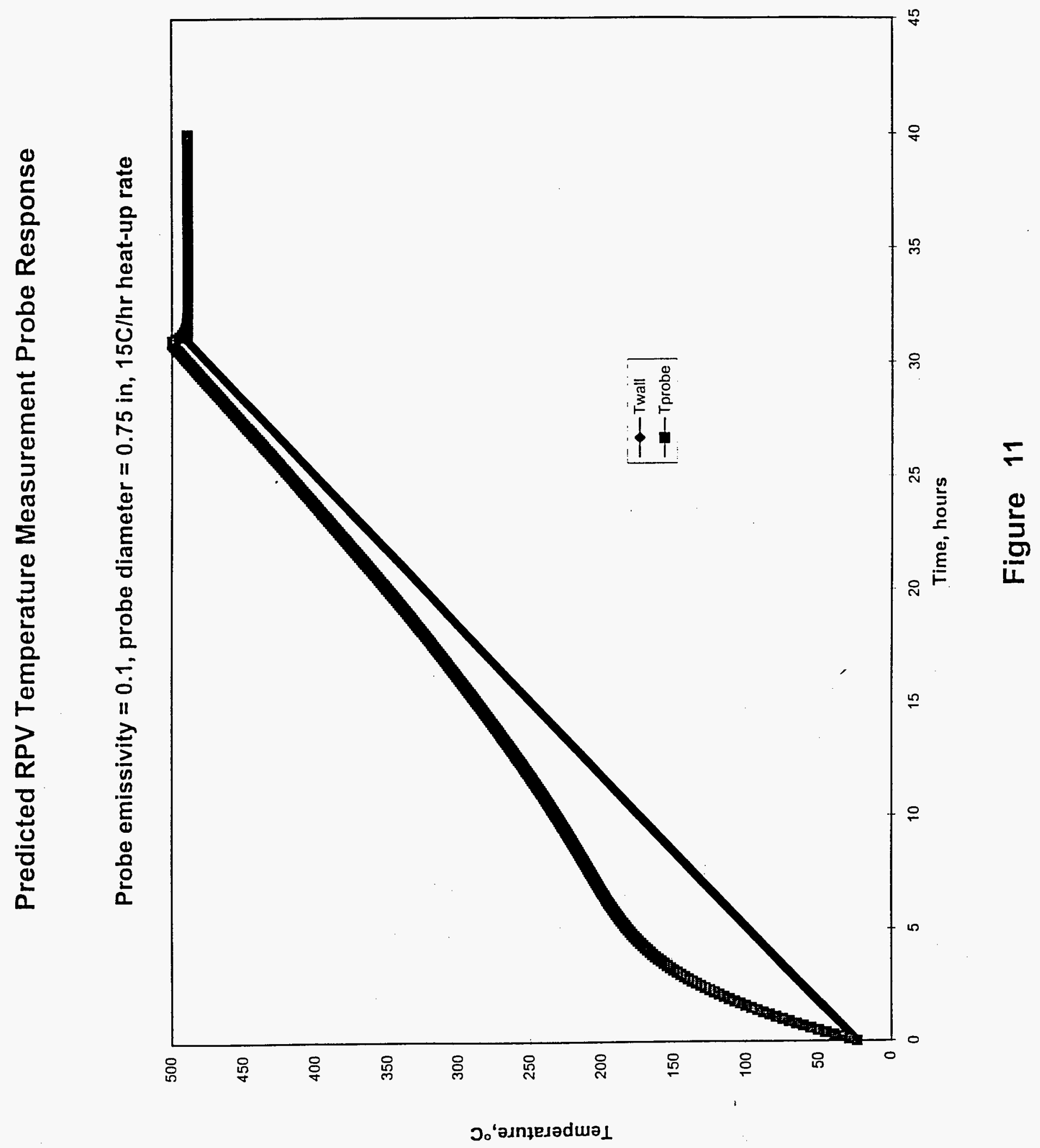




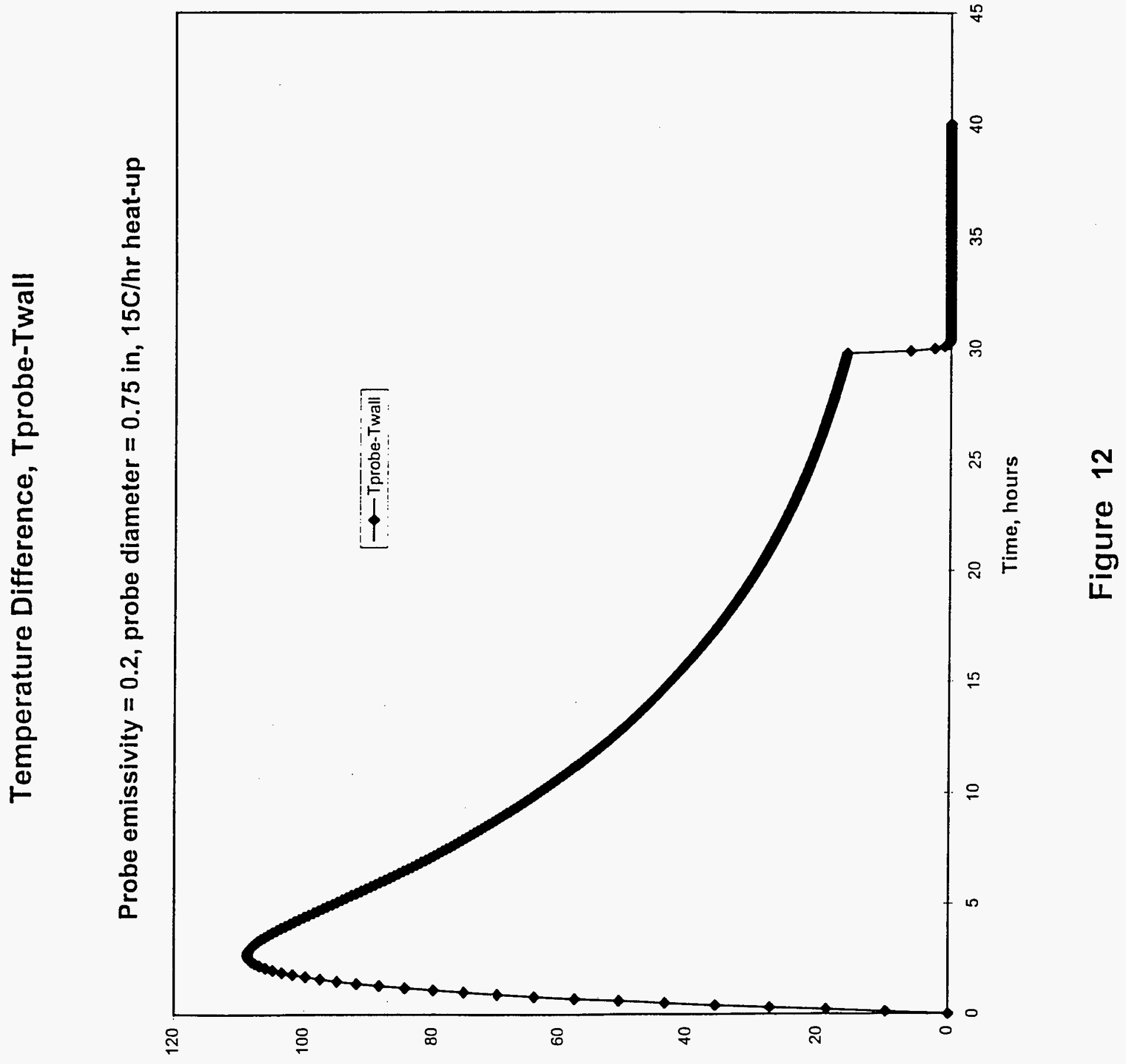

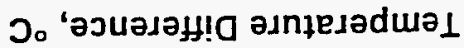




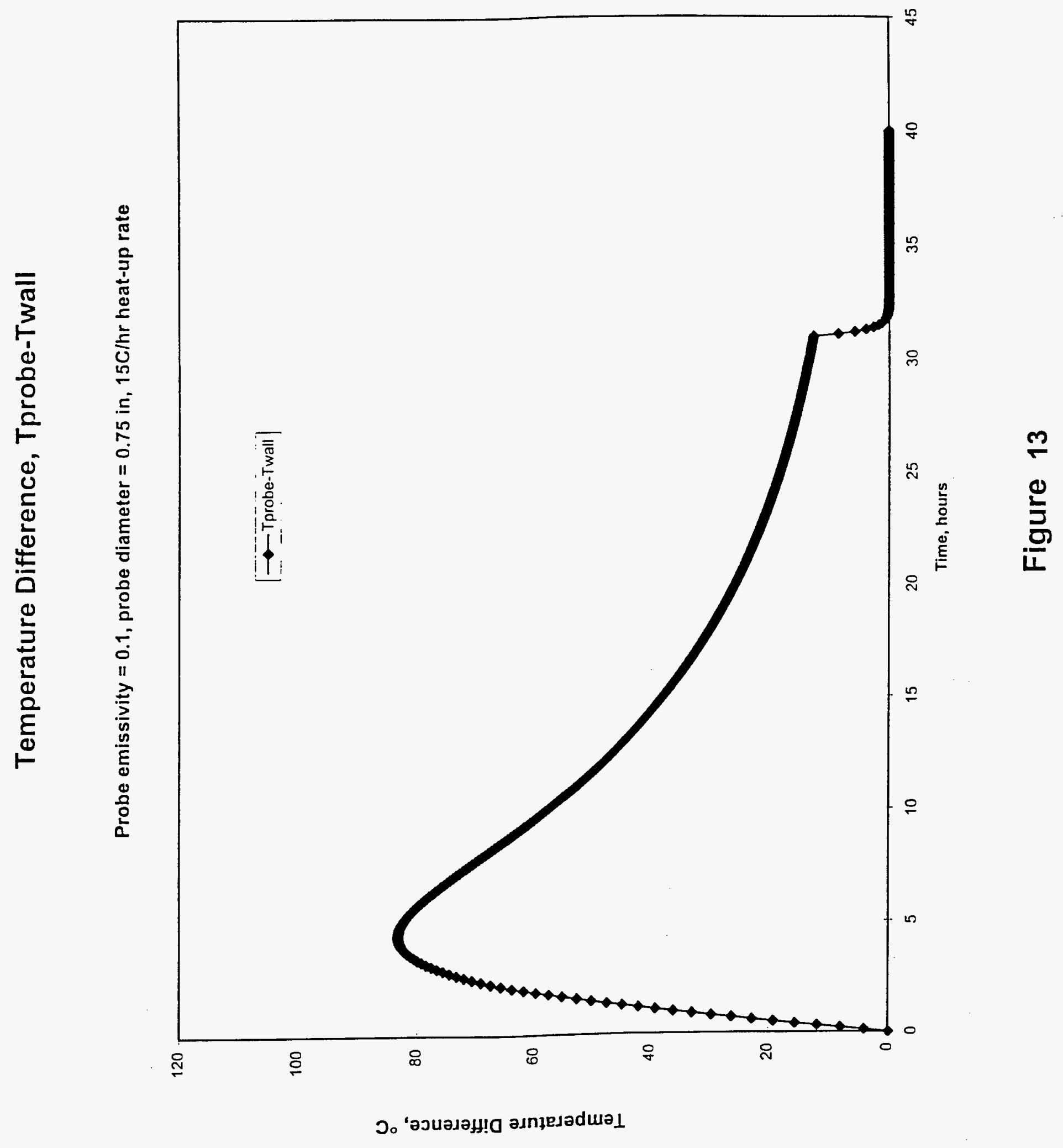




\section{M98004210}

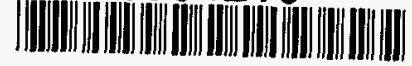

Report Number (14) $\frac{S A N D--98-078 / C}{\text { CONF-980353- }}$

Publ. Date (11)

Sponsor Code (18) DOE/DP

UC Category (19) UC-700 LDOE/ER 